\title{
Perancangan Branding "Ceripta" Kerajinan Perca Batik dengan Nilai Jual Tinggi Bagi Milenial
}

\author{
Ceicillia Jeanne ${ }^{1 *}$, Ahmad Adib ${ }^{2}$, Ani Wijayanti Suhartono ${ }^{3}$ \\ 1,2,3 Program Studi Desain Komunikasi Visual, Fakultas Seni dan Desain \\ Universitas Kristen Petra, Jl. Siwalankerto No.121-131, Surabaya \\ *Penulis korespondensi; E-mail: ceiciljean@gmail.com
}

\begin{abstract}
Abstrak
Ceripta merupakan sebuah brand kerajinan batik perca yang menyediakan produk kerajinan seperti tas dan dompet sebagai produk utama dan aksesoris pelengkap lainya, semua produk menggunakan utama batik perca sebagai bahan utama. Usaha ini dirintis berlatar belakang keinginan untuk merubah pandangan milenial lokal yang beranggapan bahwa batik itu kuno dan kain perca dianggap kurang layak untuk di-styling dengan fashion masa kini. Berdasarkan kesimpulan di atas maka perancangan yang dilakukan meliputi perancangan produk, branding dan media promosinya. Produk dirancang supaya memiliki model yang lebih modern. Sedangkan branding dirancang beserta implementasi brand bertujuan agar Ceripta sebagai brand baru dapat memiliki nyawa sehingga dapat menghidupkan brand dengan identitas yang jelas dan pas dengan target audience-nya. Perancangan promosi juga disesuaikan menggunakan media yang relevan dengan milenial. Perancangan ini diharapkan dapat meningkatkan awareness, mengembangkan bisnis dari Ceripta, dan membantu Ceripta bersaing dengan brand lokal lain.
\end{abstract}

Kata Kunci: Ceripta, Kerajinan Perca, Batik Perca, Aksesoris Batik Perca.

\begin{abstract}
Ceripta is a batik patchwork handicraft brand that provides handicraft products such as bags and wallets as the main products and other complementary accessories, all products use batik patchwork as the main material. This business was started with a desire to change the local millennials' view which assumes that batik is old-fashioned, and patchwork is deemed unfit to be styled in today's fashion. Based on the conclusions above, the design includes product design, branding, and promotional media. The product is designed to have a more modern style. Branding design along with the implementation is aimed to give a soul to Ceripta as a new brand that will liven up the brand with a strong and clear identity that fits the target audience. The promotion is also adjusted to the media that are most relevant to millennials. This design is expected to increase awareness, develop business from Ceripta, and help Ceripta compete with other local brands.
\end{abstract}

Keywords: Ceripta, Patchwork Craft, Batik Patchwork, Batik Patchwork Accessories.

\section{Pendahuluan}

Indonesia merupakan negara kepulauan yang kaya akan keberagaman dan kebudayaan, salah satu warisan kebudayaan yang banyak diminati adalah Batik Indonesia. Batik sendiri berasal dari Bahasa jawa "ambhatik", dari kata "amba" yang berarti lebar, luas, kain dan "titik" yang kemudian berkembang menjadi kata batik yang memiliki makna menyambungkan titik-titik menjadi gambar, sehingga disimpulkan bahwa kesenian batik adalah kesenian gambar di atas kain lebar untuk pakaian yang yang menjadi salah satu kebudayaan keluarga kerajaan di Indonesia zaman dahulu. Batik Indonesia telah ditetapkan oleh UNESCO sebagai warisan kemanusiaan untuk budaya lisan dan non bendawi (Masterpieces of the Oral and Intangible Heritage of Humanity) pada 2 Oktober 2009 (Kurniawan, 2020).

Batik bisa dikategorikan sebagai salah satu warisan kebudayaan yang paling populer dari Indonesia, halini bisa dilihat dari bagaimana batik terus berkembang mengikuti perkembangan jaman tanpa menghilangkan unsur budaya lokal dan dapat diterima serta digunakan oleh berbagai kalangan dan golongan usia masyarakat. Tidak hanya di Indonesia batik juga sangat populer dipasar global seperti Amerika Srikat, Jerman, Korea Selatan dan Jepang yang merupakan 4 negara importir batik 
dengan jumlah terbesar dengan menyumbangkan nilai ekspor sebesar jutaan dollar ASpada tahun 2015 (4 Negara Tujuan Ekspor Batik Indonesia, 2017). Dengan prospek dagang yang begitubesar tentu saja batik menjadi salah satu sumber mata pencarian yang menjanjikan dan diminati di Indonesia, jumlah pekerja IKM (Industri Kecil Menengah) batik mencapai 15.000 orang pada 3.782 pada tahun 2019 (Embu, 2019) belum termasuk di Industri besar dan usaha lainya yang belum terhitung, serta sumbangsih dari kegiatan ekspor dan devisa negara dari turis dan kolektor manca negara yang datang khusus untuk mencari kain batik maupun kerajinannya.

Kreasi batik yang beragam ditambah dengan pengerajin batik yang banyak jumlahnya membuat produk olahan batik sendiri terus bertambah dan berinovasi. Dengan keberagaman variasi kerajinan batik tentu juga memperluas peminatan batik dan bertambahnya permintaan pasar, namun dengan adanya pertambahan jumlah produksi maka jumlah perca batik juga akan semakin bertambah. Perca batik sering dikenal dengan sebutan perca batik ini sebenarnya sudah dilirik oleh beberapa pihak dan UKM yang kemudian mengolah ulang perca batik menjadi kerajinan batik yang memiliki nilai guna seperti keset, selimut, cempal, celemek dan lain-lain. Ada juga beberapa UKM yang mengolah perca batik menjadi kerajinan yang tidak hanya memiliki nilaiguna namun estetika seperti tas, kalung, gelang, baju, topi dan banyak lagi. Prospek dari kerajinan kain perca batik ini cukup besar dimana "Ide usaha di industri kreatif dipercaya sebagai salah satu peluang usaha yang menjanjikan pada tahun 2020" (Fajar, 2019) dengan modal yang terbilang sedikit dankeuntungan yang cukup besar. Namun spesialis pengerajin perca ini sendiri belum banyak dibandingkan dengan perca batik yang dihasilkan, peminatan dan distribusi perca batik juga bisa dibilang kurang. Mayoritas peminat kerajinan perca batik adalah konsumen luar negeri, sedangkan masyarkat lokal mayoritas membeli produk perca batik hanya yang memiliki nilai guna untuk sehari- hari seperti keset, celemek dan lain-lain yang membutuhkan banyak bahan namun harga jualnya rendah. Kerajinan perca batik merupakan kerajinanmenyambung kainkain sisa produksi batik yang memiliki tangkat kesulitan lebih dibanding dengan menggunakan kain batik yang utuh, namun sayangnyajustru dihargai lebih rendah dan dipandang sebelah mata hanya karena berbahan dasar produk sisa, padahal justru memiliki nilai juang yang lebih dan tentunya keunikan yang kuat. Sangat disayangkan apabila output yang dihasilkan sebatas memiliki nilai guna dan dipasarkan ecer dengan nilai jual rendah.

Padahal dengan menambahkan kreatifitas, promosi dan brand dapat meningkatkan nilai jual dan pemasaran secara pesat, selain itu dengan hasilkerajinan yang lebih modern dan brand dengan promosi yang kuat juga bisa memperluas pasar hinggake generasi milenial yang seringkali lebih cenderung gengsi menggunakan produk yang berbahan bekas dan tidak bermerek. Sayangnya kerajinan batik yang dipasarkan mayoritas tidak memiliki brand kuat yang mampu mengangkat nilai jual. Oleh karena tidak adanya brand yang menjadi problem pembeda mereka satu sama lain. Produk kerajinan batik tidak memiliki unique selling proposition dan brand identity yang membuat mereka layak untuk bersaing bersama handmade kerajinan modern lokal yang memiliki branding kuat dan rapi dilengkapi dengan packaging yang berperan besar dalam first experience buyer.

Perancangan ini mengangkat branding yaitu "semuanya yang berkaitan dengan hal-hal yang kasat mata dari sebuah merek mulai dari nama dagang, logo, ciri visual, citra, kredibilitas, karakter, kesan, persepsi, dan anggapan yang ada di benak konsumen perusahaan tersebut" Landa (2006) dan promosi yang adalah "memperkenalkan barang supaya konsumen menyukainya dan kemudian membelinya" Sukirno (2013). Branding yang akan dirancang secara spesifik adalah Product branding yang merupakan "usaha pemberian identitas pada sebuah produk yang mampu memengaruhi konsumen untuk memilih produk tersebut dibandingkan produk pesaing lainnya" (Novia, 2017), perancang juga akan merancang Unit selling prepotition (USP) dan promosi brand sehingga dapat memperkokoh penempatan brand pada persaingan dimarket, teori branding dikutip dari kajian teori tentang brand dan branding ("Binus", n.d.). Eksekusi yang diharapkan adalah mencapai Branding dan promosi yang sesuai sehingga bisa mengangkat penjualan dalam market milenial lokal. Perancangan Projek kerajinan batik ini akan menggunakan nama "Ceripta" yang merupakan penggabungan dari kata "cerih" dan "cipta" dimana cerih sendiri berarti sisa yang menggambarkan bahwa ciptaan kerajinan ini terbuat dari bahan sisa yaitu perca batik yang menjadikan sebuah karya sisa kembali memiliki cerita. 
Perancangan yang relevan yang pernah dilakukan sebelumnya yaitu Perancangan Visual Branding Sebagai Pendukung Promosi Produk Batik Tkat Celup UMKM Siwalankerto di Surabaya. Yang dirancang oleh Cornelli Kwanda Mahasiswi Program Studi Desain Komunikasi Visual, Fakultas Seni dan Desain, Universitas Kristen Petra, Surabaya dan Perancangan Produk Aksesoris Berbahan Batik dan Kulit Sintetis Oleh Stefani Angela Marcella Mahasiswi Desain Komunikasi Visual, Seni dan Desain, Universitas Kristen Petra. Kedua perancangan diatas dijadikan refrensi sekaligus pembeda dimana perancangan yang dibuat akan memfokuskan pada branding Ceripta serta perancangan produk aksesoris yang berbahan dasar murni kain perca yang mayoritas batik dan perca motif pelengkap lain untuk menambah estetika, membidik milenial dikarenakan kurangnyaantusiasme milenial terhadap karya seni batik terutama perca. Sedangkan perancangan milik Cornelli Kwanda adalah perancangan visual branding dan milik Stefani Angela menggunakan kulit sintetis sebagai salah satu bahan utama selain batik.

Merancang Branding dan promosi Ceripta yang merupakan kerajinan berbahan dasar perca batik yang memiliki nilai jual tinggi dan dapat berkompetisi dalam pasar milenial.

\section{Metode}

\section{Data Primer}

Segala informasi mengenai batik, kerajinan perca batik, branding yang sesuai dan strategi media promosi yang relevan dengan insight target audience.

\section{Data Sekunder}

Penunjang data primer yang dibutuhkan dalam proses perancangan branding kerajinan perca batik. Data sekunder bisa didapat dari media cetak seperti koran atau majalah. Data juga bisa didapat melalui internet dan wawancara untuk membantu proses perancangan branding.

Perancangan ini menggunakan penelitian kualitatif. Penelitian kualitatif bertujuan untuk memperoleh wawasan tentang topik tertentu dan tidak menitik beratkan pada jumlah atau banyaknya hasil, melainkan pada kualitas yang diperoleh. Data yang dikumpulkan dianalisis dengan pendekatan SWOT sehingga mempermudah untuk memperoleh pengetahuan tentang kekuatan, kelemahan, peluang dan ancaman terhadap produk, sehingga dapat di- jadikan pedoman dalam membuat branding

\section{Landasan Teori}

\section{Tinjauan Branding}

Menurut American Marketing Association, definisi merek atau brand adalah nama, istilah, tanda, symbol atau rancangan atau kombinasi dari hal-hal tersebut. Branding memiliki tujuan untuk mengidentifikasi produk atau jasa yang dihasilkan sehingga berbedadari produk atau jasa yang dihasilkan oleh pesaing (Kotler 1997:13).

Dalam membangun sebuah brand diperlukan fondasi yang kuat, caranya adalah (Rangkuti, 2004, p. 5):

1. Memiliki positioning yang tepat

Membangun positioning adalah menempatkan semua aspek dari brand value (termasuk manfaat fungsional) secara konsisten sehingga selalu menjadi nomor satu di benak pelanggan keberhasilan positioning adalah dapat menjawab keinginan dan harapan pelanggan sehingga dapat memberikan kepuasan kepada pelanggan. Dalam menciptakan positioning yang tepat dibutuhkan pengenalan dan pemahaman yang mendalam terhadap produk, perusahaan persaingan dan konsumen.

2. Memiliki brand value yang tepat

Brand value adalah nilai-nilai yang terdapat dalamsebuah brand yang digali dari nilai-nilai yang ada dalam diri pelanggannya. Ibaratnya pada sebuah pakaian positioning merupakan ukuran dan brand value merupakan warna dan model pakaian. Brand value sendiri membentuk brand personality, dan brand personality mencerminkan gejolak perubahan selera konsumen. Brand value juga mencerminkan brand equity sesuai dengan customer values.

3. Memiliki konsep yang tepat

Pengembangan konsep merupakan proses kreatif, konsep harus kuat namun juga fleksible dan dapatberubah menyesuaikan dengan daur hidup sebuah produk. konsep yang baik dapat mengkomunikasikan segala elemen dari brand value dan positioning dengan tepat, sehingga brand image yang dapat terus terbangun.

\section{Brand Equity}

Menurut Hermawan Kartajaya (2010) brand equity menjadi tolong ukur kekuatan dalam suatu brand. Brand Equity yang kuat akan 
memberikan value, baik kepada pelanggan maupun kepada perusahaan (Rita, 2018, Par. 2).

Dua dimensi yang digunakan dalam Brand Equity adalah :

1. Brand Awareness yaitu segala ingatan dan pengenalan market terhadap suatu brand.

2. Brand Association adalah segala sesuatu yang terkait dengan memori yang identik dengan suatu brand. Misalnya merchandise, marketing, promosi dan lain-lain.

\section{Logo}

David E. Carter (seperti dikutip Kurniawan, 2008, p. 7) juga menjelaskan "logo adalah identitas suatu perusahaan dalam bentuk visual yang diaplikasikan dalam berbagai sarana fasilitas dan kegiatan perusahaan sebagai bentuk komunikasi visual.

Beberapa jenis logo Wheeler (Ramanda, 2011, p. 14) yaitu:

1. Logo berupa tulisan (Wordmarks)

Logo ini berupa tulisan atau yang sering disebut dengan logotype.

2. Logo berupa huruf (Letterform)

Logo yang terdiri dari satu huruf atau lebih yang mengasosiasikan perusahaan tersebut.

3. Logo berupa emblem (Emblems)

Logo ini digunakan apabila nama perusahaan tidak dapat direpresentasikan dengan elemen visual yang sederhana.

4. Logo berupa elemen visual (Pictorial Marks) Logo berupa elemen visual yang mudah dipahami sehingga dalam waktu singkat.

5. Logo berupa simbol abstrak (Abstract/ Symbol Marks)

Logo ini terdiri atas simbol yang menimbulkan banyak asumsi, digunakan untuk memunculkan rasa ambigu.

\section{Perca}

Arti perca menurut KBBI (Kamus Besar Bahasa Indonesia) adalah perca/perca/ $\mathrm{n}$ sobekan (potongan) kecil kain sisa dari jahitan dan sebagainya; reja kain; carik kain. Jadi perca sendiri berarti sobekan atau sisa kain yang tidak terpakai dari proses jahit (Kamus Besar Bahasa Indonesia, n.d.).

\section{Batik}

Batik adalah kain yang motifnya dibuat dengan cairan malam sehingga warna tidak dapat meresap pada bagian yang berlumur cairan malam karena bagiantersebut tertutup cairan malam. Dalam pengolesan cairan malam keatas kain digunakan canting, yaitu sebuah alat kecil yang berupa mangkuk dengan ujung pipa berbahan tembaga, yang dengan gagang kayuatau bambu. Seiring dengan berkembangnya zaman, metode membatik juga semakin berkembang, mulai dari batik tulis, batik celup, batik cap hingga menggunakan printing dan mediumnya tidak hanyaterbatas kain.

\section{Milenial}

Generasi milenial disebut juga sebagai generasi Y. Orang-orang yang tergolong sebagai generasi milenial ini adalah orang-orang yang lahir di atas tahun 1980- an hingga 1997. Generasi ini berbeda dibanding yang lain karena melewati milenium kedua yang artinya melewati masa waktu seribu tahun (Yasmin, 2020, par. 5).

\section{Promosi dan Pemasaran}

Tujuan dari pemasaran adalah untuk menarik perhatian market terutama audience sehingga dapatmemperoleh pelanggan baru, dengan menyediakan suatu produk yang memenuhi keinginan dari konsumen, serta menetapkan nilai superior dengan harga yang menarik dan mendistribusikan produk dengan mudah. Kelancaran pemasaran didukung proses promosi yang efektif serta mempertahankanpelanggan yang sudah ada dengan tetap memegang prinsip kepuasan pelanggan (Putri, 2017, p. 1).

Pemilihan media memerlukan dua keputusan, yang pertama adalah media apa yang akan digunakan dan yang kedua adalah sarana media yang akan digunakan. Berikut metode yang dapat digunakan (Sitorus, et al., 2017, p. 84).

\section{Cost Per Thousand Contacts Comparison}

Metode ini memilih media berdasarkan jumlah kontak yang terjadi tanpa memperhatikan kualitas kontak yang terjadi, oleh karena itu kuantitas dan kualitas eksposur sama-sama penting bagi periklanan, kuantitas dan kualitas diukur melalui cakupan (reach), kekerapan (Frequency), dan dampak (impact).

\section{Matching of Audience and media}

Characteristics Cara lain untuk memilih media yang tepat adalah menentukan terlebih dulu target Audience kemudian membandingkan karakteristik audience dengan karakteristik berbagai media, berikut prosedurnya:

1) Mengumpulkan data yang rinci tentang pelanggan.

2) Mempelajari jangkauan (coverage) suatu media.

3) Melakukan perbandingan antara kedua informasi diatas.

4) Mengkaji pemilihan media pendahuluan itu 
dari aspek.

5) Mengalokasikan dana iklan kepada masingmasing media.

\section{Ceripta}

Ceripta adalah Brand lokal baru yang merintis usaha dalam bidang kerajinan dan aksesoris, dengan bahan baku utama perca batik. Ceripta sendiri didirikan dengan latar belakang ingin mengangkat kebudayaan batik dalam rupa perca batik, yang kemudian bisa digemari oleh milenial lokal tidak hanya pada pasar internasional. Ceripta juga ingin membantu mengurangi sampah kain terutama perca batik dengan menerapkan sustainable fashion, dimana produk yang dibuat berbahan dasar sampah kain batik yang didapatkan dari konveksi maupun penjahit, kemudian diolah menjadi produk kerajinan perca yang memiliki nilai estetika dan nilai jual bagi milenial lokal maupun pasar internasional. Sedangkan sustainable sendiri berasal dari kata sustain yang artinya berkelanjutan, sehingga sustainable fashion memiliki arti fesyen yang berkelanjutan. Maksud dari fesyen yang berkelanjutan sendiri adalah untuk membuat suatu produk terus bertahan tanpa menghasilkan sampah-sampah baru, sehingga melakukan recycling bahan perca batik menjadi kerajinan yang berguna lagi termasuk dalam salah satu gerakan sustainable fashion dengan cara tidak menambah sampah justru menambah nilai guna sampah kain batik. Ceripta ingin membuat gebrakan bagi milenial lokal yang seringkali memandang sebelah mata kreasi perca batik karena dianggap kurang modern, oleh karena itu akan melakukan perancangan produk, branding dan promosi, dengan tujuan mengubah pandangan milenial lokal bahwa kerajinan perca batik dapat digunakan seharihari tanpa terlihat kuno.

\section{Analisis Data}

Ceripta memiliki originalitas produk yang tinggi dan keunikan yang kuat dimana Ceripta merupakan produk handmade dimana satu produk dengan yang lainnya memiliki motif yang selalu berbeda dimana originalitas ini menjadi salah satu kekuatan dalam produk dan brand Ceripta. Bahan baku produk kerajinan perca sebenarnya mudah didapatkan namun tidak semua bisa digunakan, karena warna, motif dan kualitas harus dipilah. Waktu pengerjaan produksi kerajinan batik perca juga tidak cepat, butuh ketelitiandan kerapian serta harus hadir dengan banyak inovasi model produk. Namun peluang yang spesifik sendiri adalah belum banyak usaha kerajinan perca dengan desain yang modern dan relevan dengan mode anak muda, terutama apabila di-branding dan dipromosikan secara online serta relevan dengan jangkauan audiencenya. Namun ancamannya sendiri terletak pada masyarakat, terutama milenial yang memandang kerajinan perca batik kurang trendi dan lebih memilih membeli produk fast fashion, karena harga bisa dibilang lebih murah.

Ceripta adalah sebuah brand baru yang menjual produk kerajinan dengan bahan dasar perca batik dan diolah dengan model yang modern, Ceripta memiliki potensi yang baik dikarenakan oleh keunikanya dan perannya yang bukan hanya sebagai produsen dan penjual kerajinan melainkan juga menjadi salah satu faktor pengurangan sampah kain melalui daur ulang (Sustainable fashion). Namun sebagai brand yang baru Ceripta membutuhkan self branding yang kuat, sesuai dan tetap modern tanpa melepaskan nilai tradisi dan budaya, yang bisa membawa Ceripta diterima dalam pasar milenial lokal dan dapat bersaing dengan kompetitor maupun produk lokal lain. Sebagai brand yang baru Ceripta juga sangat memerlukan promosi yang dapat meningkatkan awareness dan interest dalam masyarakat yang dapat menarik menarik audience untuk mempercayai dan menggunakan Ceripta sebagai pelengkap gaya busana.

\section{Konsep Perancangan}

Kelengkapan branding Ceripta merupakan promosi offline paling simple yang melekat dengan Ceripta. Branding Ceripta diharapkan dapat membawa Ceripta memberikan feels yang modern tanpa meninggalkan unsur budaya dan tradisi juga sesuai dengan audience sehingga dapat diterima dengan baik. Branding juga bertujuan untuk memberikan kehidupan dalam usaha dan produk.

Tujuan pemasaran ini memperkenalkan brand Ceripta pada masyarakat terutama target audience dan untuk menarik perhatianmereka terhadap brand Ceripta, dengan cara menggunakan Instagram sebagai media yang paling relevan untuk saat ini. Seperti online shop pada umumnya yang melakukan endorse, give away, Instagram sponsor dan shout out for shout out sebagai online campaign untuk meningkatkan visitor akun Instagram Ceripta yang tentunya meningkatkan awareness

Tujuan promosi adalah menarik perhatian calon konsumen untuk membeli produk Ceripta 
melalui upaya penawaran produk secara direct selling maupun melalui media-media promosi.

Tujuan media adalah sebagai perantara untuk apa yang ingin disampaikan Ceripta kepada market terutama audience, sehingga media berperan penting dalam menyampaikan pesan yang ingin diutarakan oleh Ceripta kepada pada konsumennya. Dalam Ceripta sendiri tujuan media promosi yang akan digunakan adalah untuk penyampaian pesan Ceripta sebagai sebuah brand startup yang memiliki latar belakang keperdulian terhadap alam yang diwujudkan dalam hal sustainable fashion dimana perca sisa konveksi batik digunakan sebagai bahan dasar pembuatan kerajinan yang modern juga mengangkat budaya dimana perca yang dipilih difokuskan pada batik, hal ini disampaikan sebagai pengenalan terhadap brand Ceripta. Kemudian untuk memasuki market pesan yang ingin disampaikan oleh Ceripta adalah bahwa kerajinan lokal dengan membawa tradisi dan berbahandasar perca tidak menjadi halangan untuk tampil modern dan up to date.

\section{Konsumen (Target Market)}

Geografis

a. Berdomisili di Pulau Jawa (terutama tengah-timur)

b. Spesifikasi Kota Solo, Yogyakarta dan Surabaya

\section{Demografis}

a. Umur 20 - 37 tahun

b. Jenis kelamin mayoritas perempuan

c. Pekerjaan sebagai mahasiswi, pekerja maupun iburumah tangga dan sosialita

d. SES B - A
Psikografis
a. Up to date
b. Fashionista
c. Cinta kebudayaan
d. Bangga akan produk lokal

\section{Behaviour}

a. Aktif dalam sosial media

b. Suka melakukan online shopping

c. Suka mengoleksi barang-barang yang unik

\section{Program Media}

Program Instagram yang sejauh ini dinilai sesuai dengan target audience dan efektifitas promosi adalah melakukan endorse dan Instagram sponsor yangberupa story atau yang kerap disebut Snapgram.

\section{a. Endorse}

Melakukan endorse kepada influencer yang digemari oleh target audience, setelah melakukan wawancara beberapa narasumber mengatakan enggan menggunakan produk perca salah satunyadikarenakan oleh tidak adanya gambaran akan di mix and match seperti apa. Peran influencer sendiri adalah me-review produk dan juga memberikan contoh penggunaan sehingga audience lebih aware akan kulitas produk juga memiliki gambaran penggunaan produk.

\section{b. Instagram Sponsor (Snapgram)}

Berdasarkan hasil wawancara mayoritas narasumber apabila ingin mencari suatu produk, mereka akan scrolling snapgram karena snapgram lebih faktual danaktual, juga tidak monoton karena berisi cuplikan kehidupan orang lain. Sehingga sponsor Instagram yang diiklankan lewat snapgram lebih banyak dilihat dan dinilai lebih informatif.

\section{c. Give Away}

Acara yang diadakan secara online untuk menambah brand awareness melalui story audience dan peserta. Hal ini dilakukan dengan cara memposting story milikCeripta kemudian pemenangnya akan dipilih secara acak, hadiah akan dirimkan oleh Ceripta secara cuma-cuma.

\section{d. Shout Out For Shout Out}

Shout out for shout out adalah kegiatan saling mempromosikan Instagram antara kedua belah pihak. Ceripta akan bekerja sama dengan akun Instagramlain yang dinilai memiliki audience yang serupa, kemudian Ceripta akan mempromosikan Instagram partner dalam postingan Ig story demikian juga yang sebaliknya.

\section{Tujuan Kreatif}

Tujuan utama dari Branding dan promosi Ceripta adalah untuk membangun self branding yang kuat dan menjual. Selain itu sebagai brand yang baru tujuan kreatif Ceripta adalah untuk meningkatkan awareness sebagai salah satu pilihan brand yang menjual kerajinan berbahan perca batik yang berkualitas.Branding yang kuat juga membantu Ceripta untuk dapat beroleh kepercayaan audience dengan memberikan feel yang lebih trustworthy. Dengan brand dan promosi Ceripta juga diharapkan dapat membuka pandangan bagi masyarakat terutama audience tentang potensi dari sebuah kerajinan berbahan perca, sehingga tidak hanya beroleh keuntungan melainkan juga menginspirasi dan memberikan impact. 


\section{Strategi Kreatif}

\section{a. Isi Pesan (What to Say)}

Isi pesan yang ingin disampaikan melalui perancangan branding dan promosi Ceripta adalah kerajinan batik perca yang walaupun daur ulang namun berkualitas dan dapat bersaing secara modern walaupun membawa unsur budaya.

\section{b. Bentuk Pesan (How to Say)}

Melakukan serangkaian media promosi via media online dengan menggunakan tagline eksotika perca dimana produk Ceripta mengandalkan keunikan motif batik perca yang dipadupadankan dan dijadikan tas maupun dompet untuk diperdagangkan dengan nilai jual dan nilai estetika yang tinggi. Ceripta juga menggunakan \#mariberceripta sebagai ajakan mencintai produk sustainable fashion lokal, bahwa produk lokal juga bisa berkualitas dan modern.

\section{Penjaringan Ide Desain}

Produk dirancang dengan model yang lebih modis danmodern sehingga bisa di mix $n$ match dengan trend fashion yang modern, warna dan motif sudah diseleksiterlebih dahulu sebelum dijadikan sebuah produk sehingga percampurannya matching dan enak dilihat

Secara tangible Logo dibuat simple dan elegant untuk menambah kesan trendi juga memiliki nilai jual yang tinggi. Logo dibuat menggunakan font latin atau script dari tulisan untuk menonjolkan bentuk lengkung dan elastis dimana hal tersebut melambangkan sifat sebuah kain yang lembut, plastis dan bermotif sehingga tidak menggunakan font kaku. Logo diamplikasikan kedalam berbagai stationary seperti surat, kartunama, label merek produk maupun packaging. Penggunaan warna menggunakan warnacoklat bata untuk melambangkan produk ramah lingkungan dan sifat tradisional. Secara intangible yang ingin dikomunikasikan adalah sebagai brand kerajinan budaya lokal dan produk daur ulang yang ramah lingkungan. Type face yang digunakan untuk tagline adalah font sans serif yang memiliki aksen lengkung namun tetap rapi dan elegant.

Stationary yang dibuat merupakan kartu nama, label merek, stampel, surat dan amplop. Stationary dibuat menggunakan elem grafis Ceripta sehingga dalam setiap jenis stationary terdapat citra Ceripta serta keseragaman desain dalam satu brand. Stationary yang dibuat sejauh ini merupakan stationary yang sekiranya pasti akan digunakan dalam pengembangan awareness brand Ceripta pada masyarakat dan audience sehingga elemen pengulangan seperti kesamaan elemen visual sebagai motif desain dianggap perlu untuk menancapkan ciri khas brand pada benar masyarakat tentunya juga dengan variasi sehingga desain tidak membosankan.

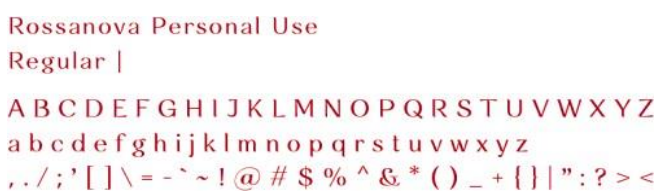

Packaging utama yang digunakan adalah pouch serutdari bahan blacu, fungsi packaging disini adalah untuk melindungi produk juga untuk meningkatkan first experience buying dari konsumen sebagai produk dan brand yang baru. Sehingga packaging mengambil andil dalam promosi serta peningkatan brand equity. Packaging sekunder yang digunakan dalam pengiriman regional menggunakan go-send maupun grabsend adalah paperbag, sedangkan dalampengiriman jasa paket seperti JNE maupun JNT menggunakan box kardus untuk meningkatkan keamana produk serta estetika.

Merchandise yang digunakan adalah stiker batik dan logo Ceripta, juga ada beberapa produk tambahan seperti karet rambut batik dan bando batik. Stiker merupakan merchandise yang paling fleksibel karena modern ini anak muda sering menempelkan stiker di laptop mereka sehingga bisa menjadi promosi cetak.

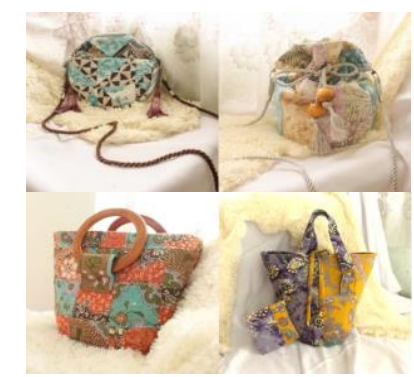

Gambar 2. Final Produk Tas Ceripta

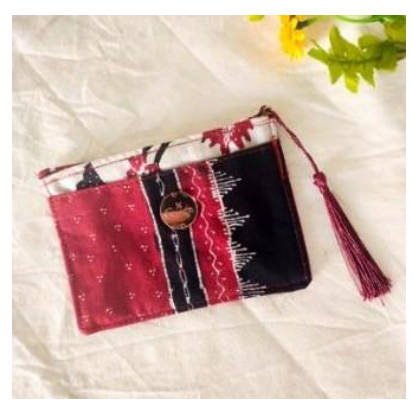

Gambar 3. Final Produk Dompet Ceripta 


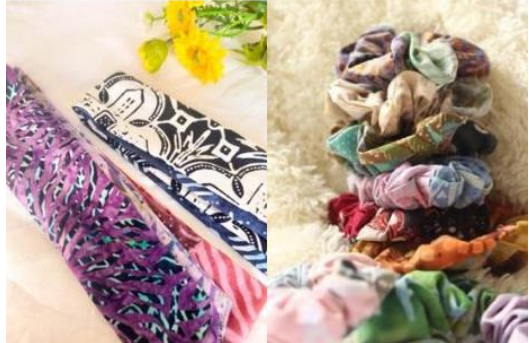

Gambar 4. Final Aksesoris Bandana dan Karet Rambut Ceripta Untuk Give-Away

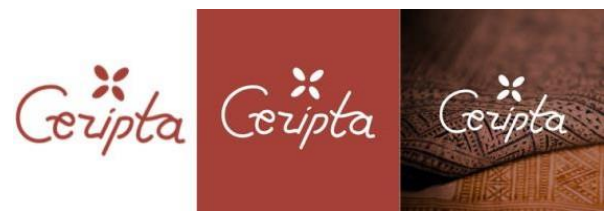

Gambar 5. Final Logo Ceripta

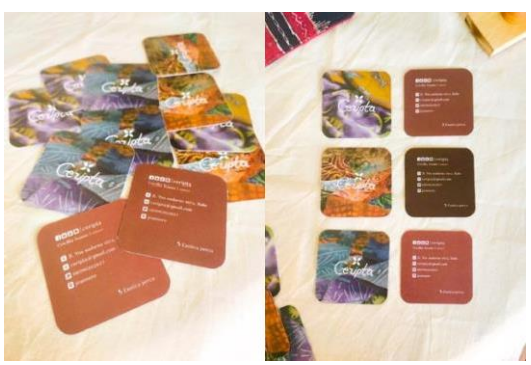

Gambar 6. Final Kartu Nama

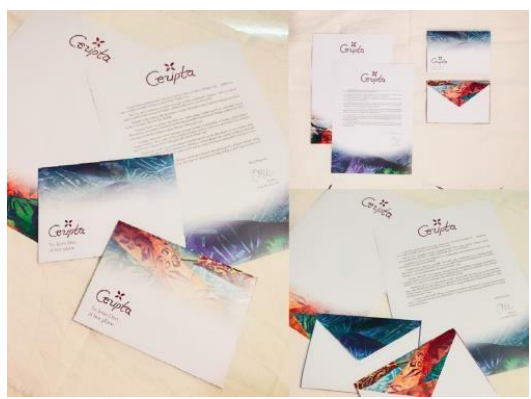

Gambar 7. Final Surat dan Amplop

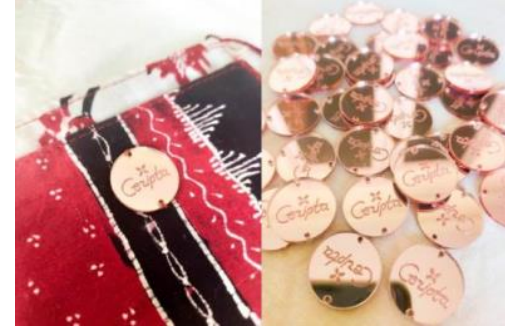

Gambar 8. Final Label Merek Akrilik

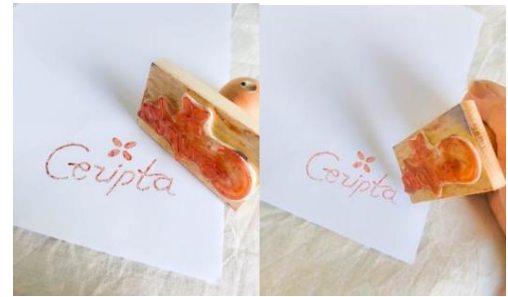

Gambar 9. Final Stampel Kayu Ceripta

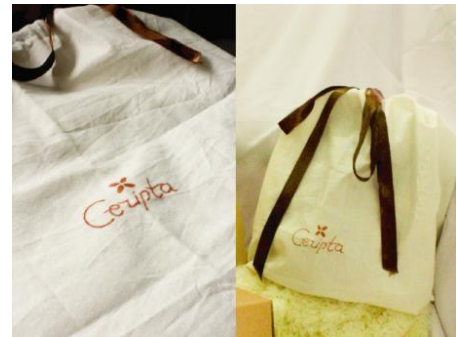

Gambar 10. Final Packaging Pouch Serut Berbahan Blachu

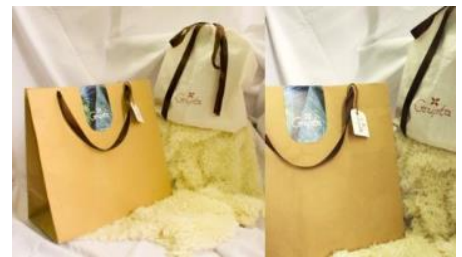

Gambar 11. Final Packaging Paperbag Berbahan Kertas Samson untuk Shipping dalam Kota

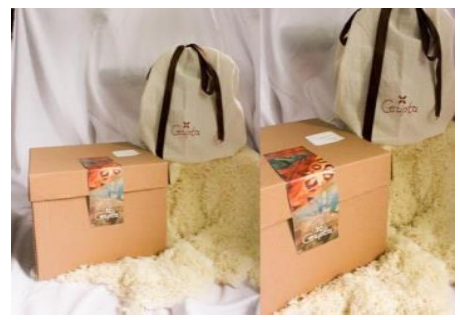

Gambar 12. Final Packaging Box Kardus Shipping Luar Kota

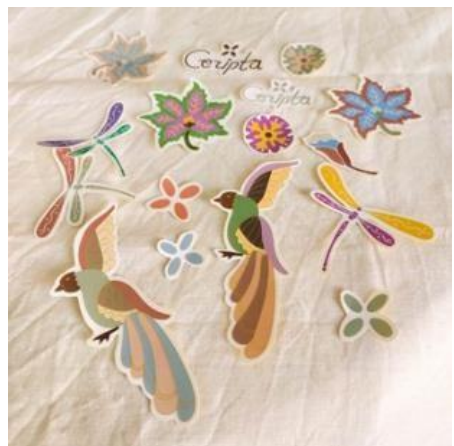

Gambar 13. Merchandise Stiker

\section{Simpulan dan Saran}

Suatu brand dapat berkembang apabila dapat menganalisa peluang pasar dan tren market dengan baik, brand tidak bisa hanya berdiri sendiri karena memiliki branding yang baik tanpa di dukung produk yang relevan dan promosi sebagai pengembangan awareness brand yang sesuai, demikian juga dengan sebaliknya produk yang bagus tidak bisa bertahan sendiri tanpa brand yang kuat dan promosi yang gencar dan promosi tidak bisa memberi impact yang besar apabila produk dan branding tidak menyesuaikan market terutama audience yang dituju. 
Ceripta merupakan suatu brand yang menyajikan produk kerajinan perca batik. Kerajinan perca batik sendiri memiliki potensi yang kuat dalam pasar dunia karena mabawa tradisi dan budaya dalam batik, serta keunikanya dalam pengolahan perca dan juga keunggulannya sebagai produk sustainable fashion, namun seiring berjalannya waktu Batik dinilai kuno oleh para milenial Indonesia dan dipandang sebelah mata karena penyajian produk yang kurang rapih dalam segi warna maupun jahitan. Produk perca batik juga seringkali bersaing dengan harga bukan karena brand yang dimiliki.

Dalam merancang suatu brand dan produk perancang harus tau benar selera target audience, hal inimemudahkan untuk menentukan tipe brand danproduk serta guide visual dari suatu rancangan brand dan produk. Ceripta dirancang sebagai solusi agar sebuah kerajinan perca batik dengan unsur tradisi itu tidak dianggap kuno namun justru bisa digunakan dalam fashion yang modern. Ceripta merancang produk batik perca dengan desain yang modern dan relevan terhadap gaya berpakaian milenial lokal, pemilihan warna dan pattern batik juga disesuaikan dengan warnawarna yang sedang popular saat ini. Ceripta juga melakukan Branding agar memiliki gambaran yang kuat dalam pasar lokal sehingga dapatbersaing dan brand dapat dikenal secara luas.

Perancangan promosi juga adalah salah satu cara untuk meningkatkan awareness juga eksistensi brand pada market. Promosi yang dilakukan Ceripta disesuaikan dengan platform online yang saat ini paling digandrungi oleh milenial juga beberapa tindakan promosi yang banyak dilakukan oleh onlineshop lokal lainya seperti Instagram sponsored, endorse dan give away yang cukup efektif dalam meningkatkan visitors, like dan followers Instagram Ceripta. Sehingga Ceripta dapan dikenal dengan luas dan terus berkembang dalam jangkauan pasar dan audience.

\section{Daftar Pustaka}

4 Negara Tujuan Ekspor Batik Indonesia. (2017). Retrieved from http://montypythondirect.com/4negara-tujuan-ekspor-batik-indonesia/

Ajrun, M. (n.d). Pengertian Batik dan Jenis Batik. Retrived from https://www.academia.edu/ 38043595/Pengertian_Batik_dan_Jenis_Batik

Binus, Library. (n.d.). Retrieved from https://library.binus.ac.id/eColls/eThesisdoc/
Bab2/Bab\%202_09-219.pdf

Fajar, M. (2019, September 17). Ingin Bisnis? Ini 5 Peluang Usaha yang Menjanjikan di Tahun 2020. Retrieved from https://www.suara.com/ yoursay/2019/09/16/200000/ingin-bisnis-ini-5peluang-usaha-yang-menjanjikan-di-tahun-2020

Kamus Besar Bahasa Indonesia. (n.d.). Kerajinan. Retrieved from https://kbbi.web.id/kerajinan

Kamus Besar Bahasa Indonesia. (n.d.). Perca. Retrieved from https://kbbi.web.id/perca

Kamus Besar Bahasa Indonesia. (n.d.). Perancangan. Retrieved from https://kbbi.web.id/perancangan

Koesno, D. (2016, October 20). Pria Kreatif Ini Merajut Untung dari Limbah Kain Perca. Retrieved from https://www.liputan6.com/ bisnis/read/2630203/pria-kreatif-inimerajut-untung-dari-limbah-kain-perca

Kotler, P., \& Amstrong, G. (2004). Dasar-Dasar Pemasaran. Jakarta: PT.Indeks.

Kurniawan, Denny. (2008). Perancangan Logo dan Mascot untuk Mendukung Promosi Wisata Kuliner Malam Warung Tradisional di Surabaya. (TA No. 00111229/DKV/2008). Undergraduate Thesis, Universitas Kristen Petra, Surabaya.

Novia. (2017, November 2). Semua Tentang Brandingyang Harus Anda Tahu. Retrieved from https://www.jurnal.id/id/blog/2017-semuatentang-branding-yang-harus-anda-tahu/

Putri, B. R. T., (2017). Manajemen Pemasaran. Denpasar: Fakultas Peternakan Universitas Udayana

Ramanda, Akhmad. (2011). Tinjauan Makna Visual Logo Bank BJB. Jurusan Desain Komunikasi Visual, Fakultas Desain. Bandung: Universitas Komputer Indonesia

Rangkuti, F. (2004). The Power of Brands. Jakarta, Indonesia: PT Gramedia Pustaka Utama

Riani, A. (208, Desember). Detail Pembeda Batik Yogya dan Solo, Sudahkah Anda Tahu?. Retrieved from https://www.liputan6.com/ lifestyle/read/3814104/detail-pembedabatik-yogya-dan-solo-sudahkah-anda-tahu

Rita. (2018). Brand Equity. Retrieved from http://bbs.binus.ac.id/internationalmarketing/2018/09/brand-equity/

Sitorus, O. F., \& Utami, N. (2017). Strategi Promosi Pemasaran. Jakarta: FKIP UHAMKA

Sukirno, S. (2013). Pengantar Bisnis Edisi Pertama (1 ed.). Jakarta: Kencana.

Yasmin, P. (2020). Milenial Jadi Kata Terpopuler di KBBI dan Google 2019, Apasih Artinya ?.Retrieved from https://news.detik.com/berita/d4849528/milenial-jadi-kata-terpopuler-dikbbi-dan-google-2019-apa-sih-artinya 